\title{
ANALISA PERHITUNGAN DAYA POMPA SENTRIFUGAL DI GEDUNG UNIVERSITAS 17AGUSTUS 1945 JAKARTA
}

\author{
M. Fajri Hidayat ${ }^{1}$, Nor fajri ${ }^{1}$ \\ ${ }^{1}$ Fakultas Teknik Jurusan Teknik Mesin, Universitas 17 Agustus 1945 Jakarta \\ fajri.hidayat@uta45jakarta.ac.id, Norfajri95@gmail.com
}

\begin{abstract}
Abstrak
Pompa adalah suatu alat atau mesin untuk memindahkan cairan dari satu tempat ketempat lain melalui suatu media perpipaan dengan cara menambahkan energi pada cairan yang dipindahkan dan berlangsung secara terus menerus. Pompa yang digunakan dalam analisa ini yaitu Pompa Sentrifugal yang terdapat di gedung Universitas 17 Agustus 1945 Jakarta. Tujuan dari analisa ini yaitu untuk mengetahui kebutuhan air pada gedung Universitas 17 Agustus 1945 Jakarta. Kebutuhan air pada gedung Universitas 17 Agustus 1945 Jakarta dihitung berdasarkan luas lantai gedung dan pemakaian setiap dosen, karyawan, mahasiswa, dan rektorat di Universitas 17 Agustus 1945 Jakarta. Hasil analisa di dapatkan total kebutuhan air bersih pada gedung Universitas 17 Agustus 1945 Jakarta adalah 1.7910 Liter/hari. Kapasitas pompa sebesar $0.06 \mathrm{~m}^{3} / \mathrm{s}$. Head total pompa sebesar $31.99 \mathrm{~m}$. Putaran poros pompa yaitu $1500 \mathrm{rpm}$. Daya pompa sebesar $0.817 \mathrm{~kW}$. Kecepatan spesifik sebesar $48.51 \mathrm{rpm}$. Dari hasil analisa dapat dinyatakan bahwa Pompa Sentrifugal yang berada di gedung Universitas 17 Agustus 1945 Jakarta sudah layak untuk digunakan.
\end{abstract}

Kata Kunci : Kebutuhan air, kapasitas pompa, pompa sentrifugal

\begin{abstract}
A pump is a device or a machine to move liquids from one place to another via a piping medium by adding energy to the fluid that is moved and continuous. The pump used in this analysis is the Centrifugal Pump contained in the building University 17 August 1945 Jakarta. The purpose of this analysis is to determine the needs of water in the building University 17 August 1945 Jakarta. Water requirement at University building August 17, 1945 Jakarta is calculated based on building floor and usage of every lecturer, staff, student, and rectorate in University 17 August 1945 Jakarta. The result of the analysis in obtaining the total clean water requirement at the building University 17 August 1945 Jakarta is 1.7910 Liter / day. The pump capacity is 0.06 $\mathrm{m}^{3} / \mathrm{s}$. The total pump head is $31.99 \mathrm{~m}$. The rotation of the pump shaft is $1500 \mathrm{rpm}$. The pump power is 0.817 $\mathrm{kW}$. Specific speed of $48.51 \mathrm{rpm}$. The results of the analysis can be stated that the Centrifugal Pump located in the building University 17 August 1945 Jakarta is feasible to use.
\end{abstract}

Keywords : Water requirement, pump capacity, centrifugal pump.

\section{PENDAHULUAN}

Pipa merupakan sarana transportasi fluida yang efektif dan efisien. Pipa memiliki berbagai ukuran dan bentuk penampang. Aliran fluida di dalam pipa mengalami penurunan tekanan sesuai dengan panjang pipa yang dilalui fluida tersebut. Pada dasarnya fungsi dari perpipaan adalah untuk mendistribusikan air bersih ke tempat-tempat yang dikehendaki dengan tekanan yang cukup.

Pompa sentrifugal banyak digunakan pada berbagai macam aplikasi industri dan beberapa sektor lain. Pompa bekerja dengan mengonversi energi mekanik menjadi tekanandan atau energi kenetik. Tekanan pada pompa meningkat dengan menghasilkan bagian dengan tekanan rendah (lebih rendah dari tekanan atmosfer) pada bagian sisi hisap pompa dan tekanan tinggi pada bagian keluaran pompa. Oleh karena rendahnya tekanan hisap maka fluida mengalir ke pompa dari reservoir.Fluida masuk secara axial melalui lubang hisap pada tengah pompa kemudian fluida tersebutberputar bersama dengan putaran sudu/impeler pompa.

Pada penelitian ini pompa yang digunakan pada gedung Universitas 17 Agustus 1945 Jakarta menggunakan pompa sentrifugal. Pompa sentrifugal yang digunakan memiliki tekanan kerja 
tinggi hingga 16 bar. Berdasarkan latar belakang diatas maka penelitian ini dilakukan untuk menganalisa perhitungan daya pompa sentrifugal pada gedung Universitas 17 Agustus 1945 Jakarta.

\section{RUMUSAN MASALAH}

Dalam analisa pompa sentrifugal di gedung universitas 17 agustus 1945 jakarta, dilakukan dengan sebaik - baiknya. Sehingga dalam analisa ini di ambil beberapa masalah yang dapat dirumuskan sebagai berikut

1. Apakah daya pompa sentrifugal sesuai dengan kebutuhan air pada setiap lantai gedung Universitas 17 Agustus 1945 Jakarta?

2. Pengaruh apa yang di hasilkan dari penggunaan pipa setiap lantai gedung Universitas 17 Agustus 1945 Jakarta?

\section{TUJUAN PENELITIAN}

Dalam analisa ini dilakukan untuk mengetahui beberapa manfaat yang dihasilkan, Untuk menganalisa kebutuhan air pada gedung Universitas 17 Agustus 1945 Jakarta dengan menggunakan pompa sentrifugal. Untuk membandingkan apakah pompa sentrifugal yang terpasang sudah sesuai.

\section{METODOLOGI PENELITIAN}

Melakukan uji operasi agar dapat mengetahui kinerja dan karakteristik pompa secara aktual guna mendapatkan parameter yang bisa diketahui dalam proses.

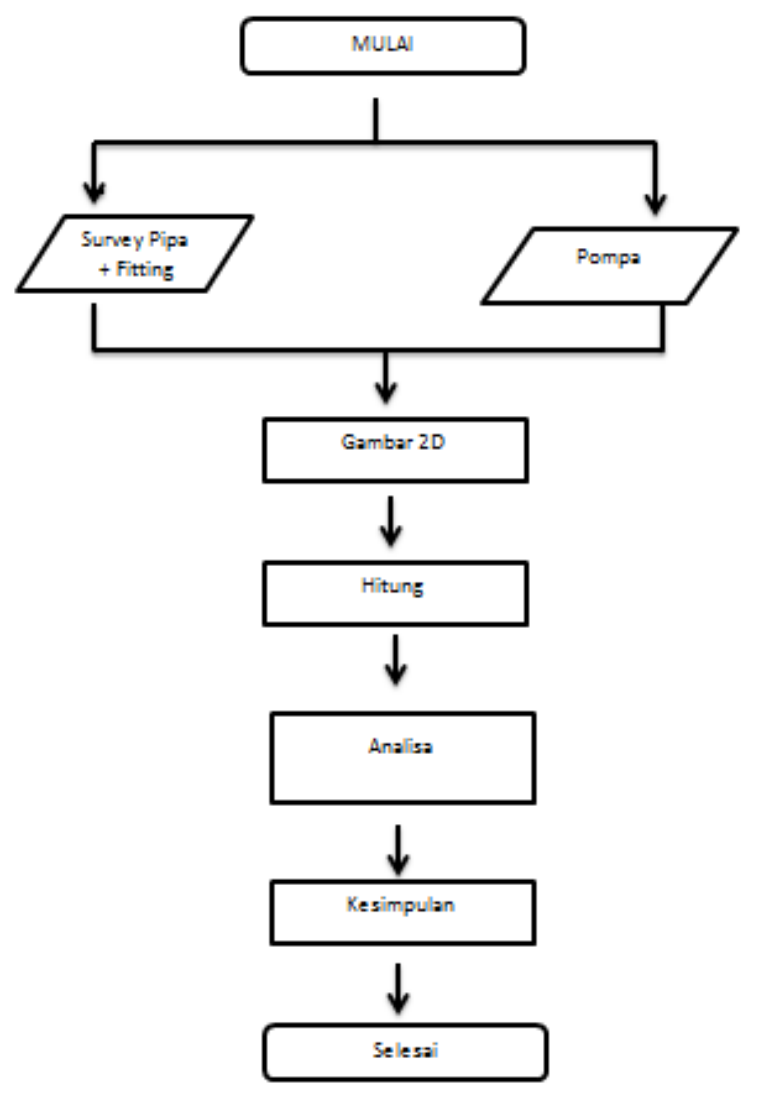


- Debit air ( Q ), diperoleh dari alat ukur rulermeter.

- Gambar rancang gedung berdasarkan aktulaisasi bangunan.

- Tekanan sisi isap dan tekanan sisi buang pada pompa ( $\left.\mathrm{Ps}_{\mathrm{s}} \mathrm{P}_{\mathrm{d}}\right)$ yang diperoleh dari alat ukur pressure gauge.

- Arus listrik ( A ) dan tegangan listrik ( V ) yang masuk pada pompa.

- Analisa hasil akhir.

- Kesimpulan sebagai penyelesaian tugas akhir

Data yang diperoleh kemudian di proses dengan beberapa langkah sehingga didapatkan hasil sebagai berikut

1. Menghitung kebutuhan air bersih menggunakan metode Jumlah penghuni dan Berdasarkan jenis dan jumlah alat plambing. Jumlah penghuni dapat diperkirakan berdasarkan luas lantai efektif. Dilihat pada tabel pemakaian rata-rata per orang setiap hari (Noer bambang, 2000:34).

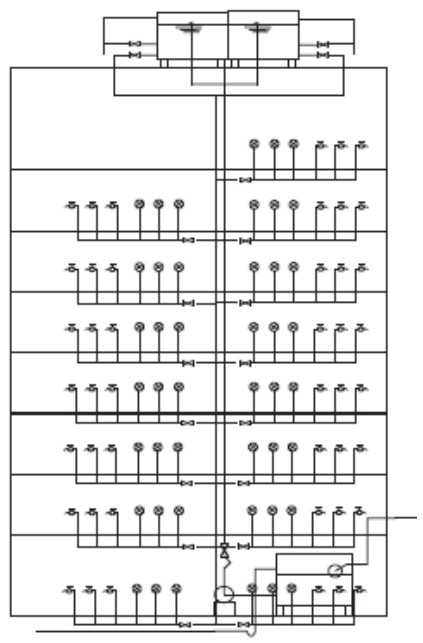

Gambar 1. Sistem Tangki Atap

2. Kapasitas pompa dapat ditentukan berdasarkan jumlah kebutuhan air maksimum dibagi dengan waktu pengoprasian pompa rata - rata perhitungan

$Q_{p=\frac{Q}{P}}$

Dimana :

$\mathrm{Q}_{\mathrm{p}} \quad=$ Kapasitas Pompa

$\mathrm{Q} \quad=$ Jumlah Kebutuhan Air

Bersih rata - rata

$\mathrm{P} \quad=$ Waktu Pengoprasian

Pompa rata - rata 8

jam/hari

3. Head total pompa adalah energi mekanik total persatuan berat zat cair dandinyatakan dalam satuan kolom zat cair dalam meter. Tinggi tekan adalah ketinggian pada kolom fluida untuk memperoleh jumlah energi yang sama deng yang dikandung dalam bobot fluida kondisi sama. Head total pompa ditentukan dari kondisi instalasi yang direncanakan dan dihitung dengan persamaan

$H=H_{a}+\Delta h p$

a. Kerugian Head Gesekan (hfsl)

$$
H s f l=\lambda \frac{\text { Is.Vis }}{2}
$$


Dimana :

$$
\begin{aligned}
\lambda= & \text { Koefisien gesek } \\
\text { Is }= & \text { Panjang Pipa isap }= \\
& 6,25 \\
\text { Ds }= & \text { Diameter dalam } \\
& \text { pipa isap }=0,035 \\
\text { Vis }= & \text { Kecepatan aliran } \\
& \text { dalam pipa isap }= \\
& 1,041
\end{aligned}
$$

Koefisien kerugian gesek ditentukan berdasarkan bilangan reynolds

Dimana :

$$
\begin{aligned}
R e & =\frac{V i s . D s}{v} \\
\mathrm{v}= & \text { viskositas kinematika } \\
& \text { zat cair }=0.801 \times 10-6 \\
& \mathrm{~m}^{2} / \mathrm{s} \text { pada } \mathrm{t}=30^{\circ}
\end{aligned}
$$

b. Kerugian Head 1 Belokan (hfs2)

$$
H f s 2=f \cdot \frac{(\text { Vis })^{2}}{2 \cdot g}
$$

c. Head Kerugian Pada Katup (hvs)

$$
H v s=f v \cdot \frac{(V i s)^{2}}{2 \cdot g}
$$

4. Kerugian Head Pada Pipa Keluar
a. Kerugian Head Gesek (hfdl1)

Dimana :

$$
H f d=\lambda \cdot \frac{L d \cdot V i d^{2}}{D d .2 \cdot g}
$$

$$
\begin{aligned}
\lambda= & \text { Koefisien kerugian } \\
& \text { gesek } \\
\mathrm{Ld}= & \text { Panjang pipa tekan } \\
& 23 \mathrm{~m} \\
\mathrm{Dd}= & \text { Diameter dalam } \\
& \text { pipa tekan }=0.025 \mathrm{~m} \\
\mathrm{Vid}= & \text { Kecepatan dalam } \\
& \text { pipa tekan }=2.01 \\
& \mathrm{~m} / \mathrm{s}
\end{aligned}
$$

b. Head Kerugian Akibat 1 Belokan (hfd2)

$$
H f d 2=f \cdot \frac{V i d^{2}}{2 \cdot g}
$$

c. Head Kerugian Pada Katup Cegah (hvd3)

$$
H v d 3=f v \cdot \frac{V i d^{2}}{2 \cdot g}
$$

d. Head Kerugian Katup Sorong (hfd4)

$$
H f d 4=f v \cdot \frac{V i d^{2}}{2 . g}
$$

e. Head kerugian Pada Pipa Keluar

$$
h f d 5=f v \cdot \frac{V i d^{2}}{2 \cdot g}
$$

5. Head Kecepatan Keluar 


$$
H v d=\frac{V i d^{2}}{2 . g}
$$

\section{HASIL DAN PEMBAHASAN}

Data yang diperoleh kemudian diolah dengan tahapan pengerjaan sehingga mendapatkan output yang diinginkan sebagai berikut:

Asumsi Pemakaian Air Pada Gedung Universitas 17 Agustus 1945 Jakarta

\begin{tabular}{|l|l|c|c|c|l|}
\hline No & \multicolumn{1}{|c|}{ Sektor } & $\begin{array}{c}\text { Pemakaian } \\
\text { Air }\end{array}$ & $\begin{array}{c}\text { Jumlah Karyawan Dan } \\
\text { Mahasiswa }\end{array}$ & $\begin{array}{c}\text { Jumlah Pemakaian } \\
\text { Air Bersih }\end{array}$ & Satuan \\
\hline 1 & Dosen & 10 & 111 & 1110 & Liter/Dosen/Hari \\
\hline 2 & Mahasiswa Pagi dan Malam & 10 & 1500 & 15000 & Liter/Mahasiswa/Hari \\
\hline 3 & OB & 15 & 30 & 450 & Liter/OB/Hari \\
\hline 4 & Karyawan & 10 & 100 & 1000 & Liter/Karyawan/Hari \\
\hline 5 & Rektorat & 10 & 35 & 350 & Liter/Rektorat/Hari \\
\hline
\end{tabular}

Yang telah ditentukan pada umumnya kecepatan aliran pipa diambil sebesar $1-2 \mathrm{~m} / \mathrm{s}$ untuk pipa diameter kecil, dan $1.5-3 \mathrm{~m} / \mathrm{s}$ untuk pipa diameter besar

\subsection{Diameter Pipa Isap}

Persamaan pipa isap dengan persamaan kontinuitas :

$Q_{p=A . s}$

Dimana :

$\mathrm{Q}_{\mathrm{p}} \quad=$ Kapasitas pompa

$\left(0.0006 \mathrm{~m}^{3} / \mathrm{s}\right)$

A $\quad=$ Luas penampang pipa

$$
\left(\frac{\pi}{4} D^{2}\right)
$$

$\mathrm{V}_{\mathrm{s}} \quad=$ kecepatan aliran rata - rata

pada penampang pipa $1 \mathrm{~m} / \mathrm{s}$

Maka :

$$
\begin{aligned}
& D_{s}=\sqrt{\frac{4 \cdot Q_{p}}{\pi \cdot V_{s}}} \\
& D \\
& s=\sqrt{\frac{4 \cdot Q_{p}}{\pi \cdot V_{s}}} \\
& D \\
& s=\sqrt{\frac{0.0024}{\pi \cdot 1}} \\
& D_{s}=\sqrt{0.00076} \\
& D_{s}=0.0275 \mathrm{~m} \\
& D_{s}=1.08 \text { inchi }
\end{aligned}
$$

Kecepatan aliran pompa dalam isap ( $\left.\mathrm{V}_{\text {is }}\right)$ 
$V_{i s}=\frac{4 \cdot Q_{p}}{\pi \cdot D_{S}^{2}}$

Dimana :

$\mathrm{Q}_{\mathrm{p}}=0.0006 \mathrm{~m}^{3} / \mathrm{s}$

$\mathrm{D}_{\mathrm{s}} \quad=0.0275 \mathrm{~m}$

Maka :

$V_{i s}=\frac{4 \cdot 0.0006}{\pi \cdot(0.0275)^{2}}$

$V_{i s}=\frac{0.0024 \mathrm{~m}^{3} / \mathrm{s}}{0.002355 \mathrm{~m}^{2}}$

$V_{i s}=1.019 \mathrm{~m} / \mathrm{s}$

\subsection{Diameter Pipa Tekan}

Dengan menggunakan rumus yang sama dengan ( 4.3.1. ) Vd mula - mula diambil $2 \mathrm{~m} / \mathrm{s}$, maka :

$$
\begin{aligned}
& D d_{=}=\frac{4 \cdot Q_{p}}{\pi \cdot V d} \\
& D d=\frac{4.0,0006}{\pi \cdot 2} \\
& D d_{=}=0.0003 \mathrm{~m} \\
& D d=0.011 \text { Inch }
\end{aligned}
$$

Kecepatan aliran pipa

Dimana :

Vid $=\frac{4 \cdot Q_{p}}{\pi \cdot D d^{2}}$

Maka :

Vid $_{=} \frac{4.0,0006}{\pi \cdot 0,0003}$

$V i d=2.54 \mathrm{~m} / \mathrm{s}$

\subsection{Head Total}

$h f d 5=f v \cdot \frac{V i d^{2}}{2 \cdot g}$

Dimana :

$f v=1.0$

Maka :

$h f d 5=1.0 \cdot \frac{\left(2.01 \frac{\mathrm{m}}{\mathrm{s}}\right)^{2}}{2.9,8 \mathrm{~m} / \mathrm{s}^{2}}$

$h f d 4=0.2 \mathrm{~m}$

Sehingga :

$$
\begin{aligned}
& h l d=h f d 1+h f d 2+h f d 3+h f d 4+h f d 5 \\
& h l d=7.5 m+0.24 m+0.288 m+0.028 m+0.2 m
\end{aligned}
$$

$$
h l d=8.34 \mathrm{~m}
$$

Berdasarkan perhitungan diatas maka total head kerugian adalah :

$h l=h l s+h l d$

$h l=0.4595 m+8.34 m$

$h l=8.799 m$

Hd = head statis isap + head 


$$
=4 \mathrm{~m}+19 \mathrm{~m}
$$

$=23 \mathrm{~m}$

$H v d=\frac{V i d^{2}}{2 . g}$

$H v d=\frac{\left(2.01 \frac{\mathrm{m}}{\mathrm{s}}\right)^{2}}{2.9,8 \mathrm{~m} / \mathrm{s}^{2}}$

$H v d=0.2 \mathrm{~m}$

Berdasarkan perhitungan diatas maka besarnya head total adalah :

$H=8.799 m+23 m+0+0.2 m$

$H=31.99 m$

\subsection{Daya}

Untuk pompa standart daya nominal penggerak mula dapat ditentukan dengan diagram pemilihan pompa umum (lampiran). Daya nominal penggerak mula dapat juga ditentukan dengan persamaan :

$P m=\frac{P s(1+a)}{n_{1}}$

Dimana :

Ps = Daya poros $=$

$\mathrm{Pm} \quad=$ Daya Nominal Penggerak mula $(\mathrm{kw})$

$\alpha \quad=$ Faktor cadangan $=$

$\eta_{1} \quad=$ Efisiensi transmisi $=1$ (pompa dikopel langsung dengan batang penggerak mula) Maka :

$P m=\frac{0.431 k w(1+0.2)}{1}$

$P m=0.517 \mathrm{kw}$

\section{KESIMPULAN}

Dari uraian - uraian dan perhitungan pada bab sebelumnya, analisa pompa sentrifugal untuk mendistribusikan air bersih pada gedung Universitas 17 Agustus 1945 Jakarta. Dapat ditarik beberapa kesimpulan sebagai berikut :

1. Pompa yang di analisa mempunyai :

- Kapasitas

$$
=0,0006 \mathrm{~m}^{3} / \mathrm{s}
$$

- $\operatorname{Head}(\mathrm{H})$

$$
=31,99 \mathrm{~m}
$$

- Putaran (n)

$=1500 \mathrm{rpm}$

- Daya pompa (Pm)

$$
=0.517 \mathrm{Kw}
$$

2. Dengan kecepatan Spesifik $(n s)=48,51 \mathrm{rpm}$ maka pompa ini memiliki impeller radial

3. Berdasarkan kapasitas pompa di titik nol maka head pompa berada pada titik tertinggi, pada saat kapasitas semakin besar maka head akan mengalami penurunan dan daya mengalami kenaikan, dan saat kapasitas standart maka efisiensi berada pada titik tertinggi.

4. Berdasarkan analisa yang dilakukan pada bab sebelumnya bahwa Pompa yang direncanakan sudah layak untuk digunakan pada Gedung Universitas 17 Agustus 1945 Jakarta yang sesuai dengan analisa skripsi ini dengan perbandingan kapasitas pompa yang terpasang $1,5 \mathrm{Kw}-2,2 \mathrm{Kw}$ dengan hasil analisa $0.517 \mathrm{Kw}$. 
SARAN

\section{DAFTAR PUSTAKA}

Jack B. Evett, Cheng Liu. 1987. Fundamentals of Fluids Mechanics. Mc Graw Hill. New York, Hal. 80.

Jack B. Evett, Cheng Liu. 1987. Fundamentals of Fluids Mechanics. Mc Graw Hill. New York, Hal. 100. Edisi 19.

Jack B. Evett, Cheng Liu. 1987. Fundamentals of Fluids Mechanics. Mc Graw Hill. New York, Hal. 213. Edisi 22.

M. Orianto, W.A. Pratikto. 1989. Mekanika Fluida I. BPFE Yogyakarta, Hal. 80.

M. White, Frank dan Hariandja, Manahan. 1988. Mekanika Fluida (terjemahan). Erlangga, Jakarta.

Sagala, Antonyster. 2008. Perancangan Instalasi Pendistribusian Air Minum Pada Perumnas Taman Putri Deli, Namorambe - Kabupaten Deli Serdang. Departemen Teknik Mesin Fakultas Teknik. Universitas Sumatera Utara Medan.

Sihite, Alexander Nico P dan A. Halim Nasution. 2013. Analisis Kerugian Head Pada Sistem Perpipaan Bahan Bakar Hsd Pltu Sicanang Menggunakan Program Analisis Aliran Fluida. Fakultas Teknik. Universitas Sumatera Utara. Jurnal e-Dinamis. Volume 4, No.4

Sularso, Haruo Tahara. 2000. Pompa dan Kompressor : Pemilihan, Pemakaian dan Pemeliharaan. PT Pradnya Paramitha. Jakarta, Hal 31.

Sularso dan Haruo Tahara. 2004. Pompa dan Kompresor. Jilid 8. Penerbit PT. Pradnya Paramita. Jakarta. Hal 6.

Sumardiyanto, D. and Susilowati, S.E., 2018. Pengaruh Tekanan Pompa Bahan Bakar Tekanan Tinggi terhadap Kinerja Mesin. Jurnal Kajian Teknik Mesin, 3(2), pp.98-105.

Universitas Mataram. Jalan MajapahitDinamika Teknik Mesin, Volume 2 No.2

Viktor L. Streeter, Arko Prijono. 1990. Mekanika Fluida Jilid 1, Edisi delapan. PT Erlangga. Jakarta, Hal. 200.

Zainudin, I Made Adi Sayoga, dkk. 2012. Analisa Pengaruh Variasi Sudut Sambungan Belokan Terhadap Head Losses Aliran Pipa. Fakultas Teknik. 